\title{
Commuting Mode Choice Behaviour Study and Policy Suggestions for Low-Carbon Emission Transportation in Xi'an (China)
}

\author{
Liu YANG, Yuanqing WANG
}

\begin{abstract}
This study established the commuting mode choice models in the typical Chinese city of Xi'an by using the Logistic regression method. Results show that commuters will transfer from the walking, bicycle, electric-bicycle/motor or bus to the car if the commuting distance, household income or the car availability increase; commuters will transfer from the walking, bicycle, electric-bicycle/motor to the car and transit if the commuting distance increases; compared with transit, the shorter driving time is the significant factor for the commuters choosing cars. The findings indicate that there is the necessity of great investment in the public transit with high-quality services to shorten the traveling time, combined with measures of car restriction, parking control, road congestion charging and transit priority lanes for the low-carbon emission transportation development in Chinese cities. The findings in the typical city of Xi'an will provide reference value for other cities in the world.
\end{abstract}

Keywords: commuting mode choice behaviour; logistic regression model; low-carbon emission transportation; policy suggestion

\section{INTRODUCTION}

Urban transportation carbon emissions have become the common issues faced with the cities in the world, which have greatly attracted global attentions. The fourth assessment report of the Intergovernmental Panel on Climate Change (IPCC) have pointed out that the recent global warming is caused by the greenhouse gas (GHG) emissions generated by human activities [1]. Carbon dioxide $\left(\mathrm{CO}_{2}\right)$ is the single most important greenhouse gas, which contributes about $65 \%$ of total GHG emissions [2]. In addition, the transportation sector is a major source of $\mathrm{CO}_{2}$ emissions and currently contributes $20-25 \%$ of global $\mathrm{CO}_{2}$ emissions, and its global share is projected to rise to $30-50 \%$ by 2050 [3].

Due to commuters' concentrated travel time and intensive travel demands, commuting trips have brought large amounts of $\mathrm{CO}_{2}$ emissions in the Chinese cities. Moreover, during the rapid economic growth, fast urbanization and motorization in China, Chinese cities will continuously be faced with the challenges of the increased car ownership and car uses and the decreased uses of the low-carbon emission and non-motorized traffic modes. Therefore, commuting mode choice behaviour study is important for the transport of $\mathrm{CO}_{2}$ emission reductions and the low-carbon emission transportation development in Chinese cities. The goal of this study is to make comparative analysis of the mode choice behaviours among the car and the low-carbon emission and nonmotorized traffic modes (walking, bicycle, electricbicycle/motor, bus), to reveal the characters and changing tendencies of the mode choice behaviours in the commuting trips, and to provide the countermeasures for the policy makings in the low-carbon emission transportation development in Chinese cities.

Apart from Beijing, Shanghai, Guangzhou and Shenzhen in China, there is extraordinary rapid development in other cities ranking from the $5^{\text {th }}$ to the 65 th. These cities are not the largest but are among the fastest growing cities in the world [4]. Xi' an is the representative of these cities in China. The city of Xi' an sprawled by the ring roads and radial roads, which is the typical character of the city sprawl in China. Also, China is rich in history and culture, and Xi'an is one of the famous ancient cities in China and in the world with many heritages, rich cultures, and protected historical districts in the city's centre area. Xi'an needs to accommodate old traditions and modern development during the rapid urbanization and motorization. These characters are similar with many other cities in China. Therefore, Xi'an was chosen as the representative of Chinese cities in this study.

Previous studies have manifested that age, gender, income, car ownership, cities' GDP and population will have influences on the mode choice behaviours. The increasing income of the residents in Yangon in Burma will make the car use increases and the decreases of the public transit [5]. In Foshan city in China, people between 35 and 55 years old are the main users of the car mode; males prefer to choose cars and motorcycles; people with high income prefer to choose cars while people with low income prefer to choose bicycle and bus [6]. In the 112 middle sized cities in Europe, the increase of the car ownership and cities' GDP will increase the car uses; the increase of the lengths of the bicycle lanes will increase the bicycle uses; and the increase of the bus number and population will increase the bus uses [7]. The commuting travel survey results in New York show that the effective way to reduce the car uses is increase of the bus frequency and speed and making the traffic congestions prolonging the travel time of using cars [8]. In Barcelona of Spain, increasing the fees of using cars will effectively control the increases of the car uses [9]. Job-housing balance will decrease the commuting distance, motorized commuting trips and transport carbon emissions in Beijing of China [10]. The increasing of the household income and the number of the employees will increase the household car ownership while the increase of the fees of buying cars and population will decrease the car ownership [11]. In the previous studies, there is a lack of the comparative analysis of the mode choice behaviours among the users of the car and the lowcarbon emission and non-motorized traffic modes. Also, previous studies lack of revealing the characters and changing tendencies of the mode choice behaviours in the commuting trips in Chinese cities, which are now under rapid economic growth, quick motorization and urbanization. Therefore, this study will establish the 
commuting mode choice models in the typical city of Xi'an, including walking, bicycle, transit, electricbicycle/motor, and car modes, and will investigate the important factors of the commuting mode choices. Also, this study will make the comparative analysis based on the model estimation results, explore the characters and changing tendencies of the commuting mode choice behaviours, and provide the policy suggestions in the lowcarbon emission transportation development. The findings in the typical city of Xi'an will greatly contribute to the transportation carbon emissions reduction in Chinese cities and the similar cities in the developing countries and will also contribute to the mitigation of the global climate changes.

\section{DATA COLLECTION}

The household surveys were implemented in the main urban area of Xi'an in 2012. Simple random sampling was carried out in each traffic zone. On average, nine to ten households were surveyed in each zone and a total of 1501 households were surveyed. The questionnaire included the commuting mode, distance, time, household location, work place, age, gender, education level, type of the work unit, household income, and household car availability. The descriptive statistical results of the samples are shown in Tab. 1. Survey results show that the proportions of the commuters working in the government, public institutions and enterprises are respectively $4 \%, 21 \%$, and $62 \%$. The average household annual income of the samples is about US\$14,634. These characteristics are similar to the overall level of Xi'an city. According to the Xi'an statistical yearbook of 2012, the percentages of commuters working in government, public institutions and enterprises are $5.9 \%, 17.8 \%$ and $76.4 \%$, respectively. The household annual income is about US\$13,791[12]. These results indicate that the samples represent well the overall commuters and households in Xi'an. Commuting mode survey results in Tab. 1 showed that the transit trips take the largest percentage (41\%), the second largest is the car trips $(28 \%)$, and the next is walking $(18 \%)$, while, there exist small percentages of the bicycle $(3 \%)$ and electricbicycle/motor trips $(8 \%)$.

Table 1 Descriptive statistical result of the individual/household socio-economic characteristics and mode choices

\begin{tabular}{|c|c|c|c|c|c|c|c|}
\hline & Levels & $N$ & $\%$ & Lev & & $N$ & $\%$ \\
\hline & Male & 1088 & 56 & Household traffic vehicles & Car availability & 701 & 47 \\
\hline Gender & Female & 864 & 44 & & $<$ US\$10,000 & 432 & 29 \\
\hline & $18-35$ & 971 & 50 & & US $\$ 10,000-16,000$ & 823 & 55 \\
\hline Age & $35-55$ & 907 & 46 & Household annual income & US\$16,000-20,000 & 447 & 30 \\
\hline & $>55$ & 64 & 3 & & US $\$ 20,000-40,000$ & 175 & 12 \\
\hline & Government & 78 & 4 & & $>$ US $\$ 40,000$ & 49 & 3 \\
\hline & Public institution & 407 & 21 & & Walking & 344 & 18 \\
\hline Work unit type & Foreign enterprise & 26 & 1 & & Bicycle & 52 & 3 \\
\hline & Private enterprise & 869 & 45 & & Transit & 795 & 41 \\
\hline & State-owned enterprise & 314 & 16 & Traftic mode & Electric-bicycle/motor & 159 & 8 \\
\hline & Middle school/high school/technical secondary school & 526 & 27 & & Car & 554 & 28 \\
\hline Fducation leyel & College & 478 & 24 & & Other & 36 & 2 \\
\hline Education level & Bachelor's degree & 789 & 40 & & & & \\
\hline & Master's/PhD degree & 145 & 7 & & & & \\
\hline
\end{tabular}

\section{COMMUTING MODE CHOICE MODEL ESTABLISHMENT}

Logistic regression method is commonly used in the mode choice modelings [7, 8]. Binary logistic regression used the cumulative logistic probability function, which assumes the possibility of $Y=1$ is $P$, then the other one of $Y=0$ is $(1-P)$. Since $Y$ is either 0 or 1 , the dependent variable $Y$ could be regardeded as a result of a Bernoulli trial. By natural logarithm processing of $P /(1-P)$, we can get $\ln (P /(1-P))$, that is to do logit transfer of $P /(1-P)$. We marked it as Logit $P$ and the value of $\operatorname{Logit} P$ is between infinity and infinitesimal. Then we establish the linear regression model using Logit $P$ as the dependent variable shown as the following [13],

$\operatorname{Logit} P=\alpha+\sum_{k=1}^{K} \beta_{k} x_{k} \quad(k=1,2, \ldots, K)$

Then we can get,

$$
P=\frac{\operatorname{Exp}\left(\alpha+\beta_{1} x_{1}+\beta_{2} x_{2}+\beta_{3} x_{3}+\ldots+\beta_{k} x_{k}\right)}{1+\operatorname{Exp}\left(\alpha+\beta_{1} x_{1}+\beta_{2} x_{2}+\beta_{3} x_{3}+\ldots+\beta_{k} x_{k}\right)}
$$

The maximum likelihood estimation method is used for the model estimation. In Eq. (1) and (2), $\alpha$ is the constant and $\beta_{k}$ is the coefficient.

Logistic regression models of the commuting mode choices are shown below,

$\ln \left(\frac{p(x)}{1-p(x)}\right)=\alpha+\sum_{k=1}^{K} \beta_{k} x_{k}$

In Eq. (3), $p(x)$ is the probability of choosing the mode of walking, bicycle, transit, electric-bicycle/motor, and car. The independent variables include the socio-economic characteristics of the individuals and households (age, gender, education level, type of the work unit, household income, and household car availability) and the commuting distance. In the modeling process, all the potential independent variables were considered. Then, based on the interim modeling results, less significant independent variables were removed. The best logistic regression models of the commuting mode choices were established with all significant variables, shown in Tab. 2 . The values of $R$ square and Log Likelihood show that the models have passed the statistical tests and have good levels of goodness of fit. 


\section{MODEL RESULT AND DISCUSSION}

Five commuting mode choice model results are shown in Tab. 2. In the walking mode choice model, female commuters, commuters without a car and with short distance prefer to use this mode. In the bicycle mode choice model, commuters more than 55 years old with short commuting distance prefer to use the bicycle. In the transit mode choice model, commuters with the age between 18 and 35 years old, with household annual income between US\$10,000 and US\$16,000, and with long commuting distance prefer to use this mode, while commuters with car availability and with the household annual income of more than US $\$ 16,000$ do not prefer to use this mode. In the electric bicycle/motor mode choice model, male commuters, commuters graduated from middle school/high school/technical secondary school or college, without a car, and with short commuting distance prefer to use this mode. In the car mode choice model, female commuters and commuters of the age between 18 and 35 do not prefer this mode, while, commuters with car availability, with bachelor's degree, with long commuting distance, and with household annual income between US\$16,000 and US\$40,000 prefer to use car.

Table 2 Commuting mode choice model results

\begin{tabular}{|c|c|c|c|c|c|}
\hline & Walking & Bicycle & Transit & $\begin{array}{c}\text { Electric- } \\
\text { bicycle/motor }\end{array}$ & Car \\
\hline Constant & $0.317(0.036)$ & $-2.800(0.000)$ & $-0.336(0.007)$ & $-2.607(0.000)$ & $-4.308(0.000)$ \\
\hline \multicolumn{6}{|l|}{ Gender } \\
\hline Male & & & & $0.531(0.003)$ & \\
\hline Female & $0.460(0.001)$ & & & & $-1.236(0.000)$ \\
\hline \multicolumn{6}{|l|}{ Age } \\
\hline $18-35$ & & & $0.441(0.000)$ & & $-0.474(0.000)$ \\
\hline$>55$ & & $1.146(0.021)$ & & & \\
\hline \multicolumn{6}{|l|}{ Education level } \\
\hline $\begin{array}{l}\text { Middle school/high school/technical } \\
\text { secondary school }\end{array}$ & & & & $1.348(0.000)$ & \\
\hline College & & & & $0.459(0.066)$ & \\
\hline Bachelor's degree & & & & & $0.571(0.000)$ \\
\hline Household car availability & $-0.248(0.062)$ & & $-1.372(0.000)$ & $-0.943(0.000)$ & $4.035(0.000)$ \\
\hline \multicolumn{6}{|l|}{ Household annual income } \\
\hline US\$10,000-16,000 & & & $0.262(0.033)$ & & \\
\hline US $\$ 16,000-20,000$ & & & $-0.528(0.008)$ & & $0.453(0.021)$ \\
\hline US\$20,000-40,000 & & & $-1.163(0.005)$ & & $1.437(0.000)$ \\
\hline$>$ US\$40,000 & & & $-0.051(0.008)$ & & \\
\hline Commuting distance $(\mathrm{km})$ & $-0.785(0.000)$ & $-0.293(0.000)$ & $0.174(0.000)$ & $-0.104(0.003)$ & $0.157(0.000)$ \\
\hline Log Likelihood & -669.898 & -227.261 & -1138.765 & -490.385 & -716.369 \\
\hline$\chi^{2}$ & 413.34 & 24.03 & 310.84 & 114.14 & 851.85 \\
\hline Pseudo $R^{2}$ & 0.228 & 0.050 & 0.120 & 0.104 & 0.373 \\
\hline
\end{tabular}

Note: numbers in brackets refer to $p$-value, which is related to the significance level.

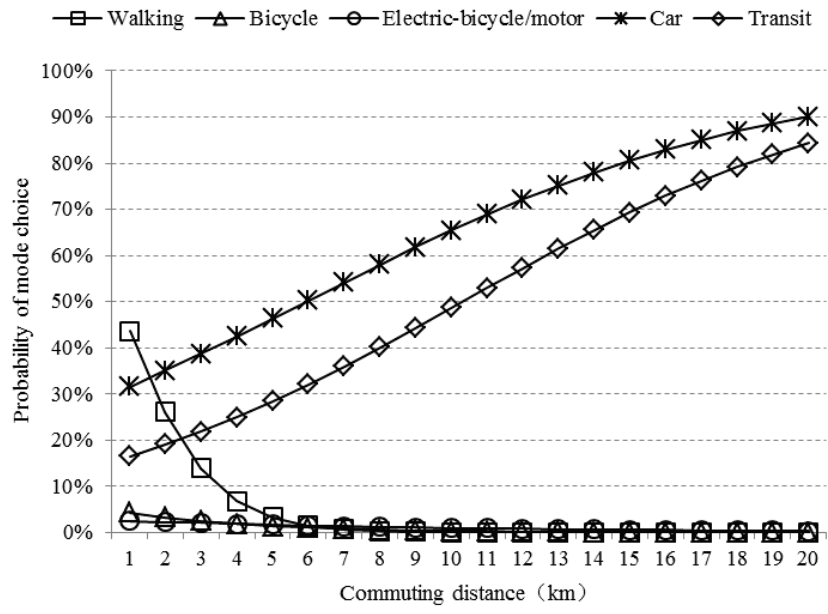

a)

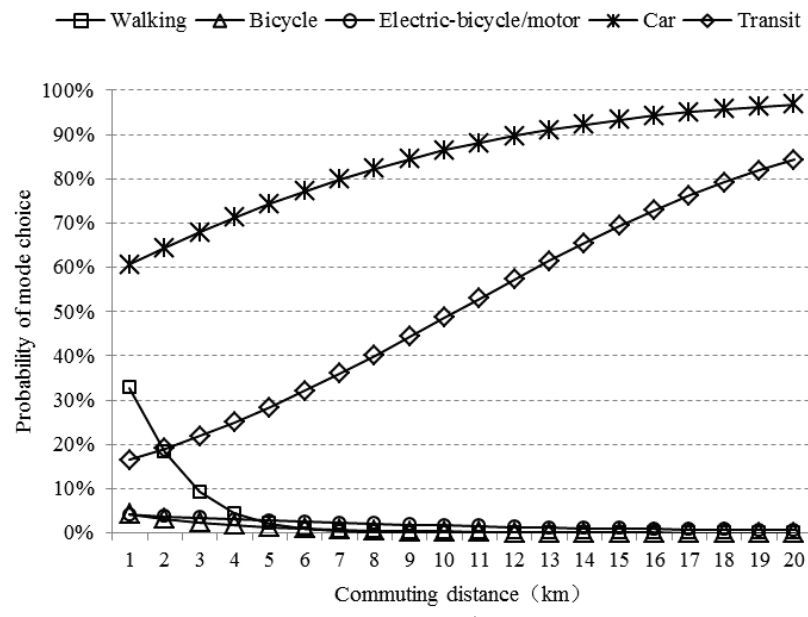

b)

Figure 1 Commuting mode choices changes with the trip distances

Also, it is seen from the results that the coefficients of the commuting distance in the walking, bicycle, and electric-bicycle/motor mode choice models are all negative $(-0.785,-0.293,-0.104)$. This indicates that the shorter the commuting distance, the more probability of using these three modes. However, the coefficient of the commuting distance in the car and transit mode choice model is positive $(0.174,0.157)$. This indicates that the longer the commuting distance, the more probability of using car and transit. These four mode choice models' comparisons show that when there is increasing commuting distance, there will be increasing probability of using car and transit and there will be transfers from the modes of walking, bicycle, and electric-bicycle/motor to the car and transit mode. 
The model application results in Fig. 1 show the changing tendency of the probabilities of the mode choice as the commuting distance increases. The scenarios in Fig. $1 \mathrm{a}$ and $1 \mathrm{~b}$ are the female and male commuters of the age between 18 and 35, with car availability, and with the household annual income between US\$16,000 and US\$20,000. The results in Fig. 1a indicate that when the commuting distance is shorter than $2 \mathrm{~km}$, there is larger probability of walking than using the car, transit, bicycle, and electric-bicycle/motor. Also, it is seen that there is sharp increasing probability of choosing cars and transit and sharp decreasing probability of walking. And, when the commuting distance is more than $2 \mathrm{~km}$, there is the largest probability of choosing car, secondly the transit, and next the walking, bicycle, and electric-bicycle/motor. There is similar tendency in Fig. 1b. The difference between Fig. 1a and $1 \mathrm{~b}$ lies in that the probability of the female commuters choosing walking is larger than that of the males.

Fig. 2 shows the average commuting distance and time by modes. The commuting distance and time by walking is the shortest, secondly is the bicycle and the electric-bicycle/motor. Compared with transit, the average commuting distance of cars is longer, while the commuting time is shorter. This indicates that, compared with the transit, the shorter time of the car mode is one of the important factors of choosing this mode for commuting.

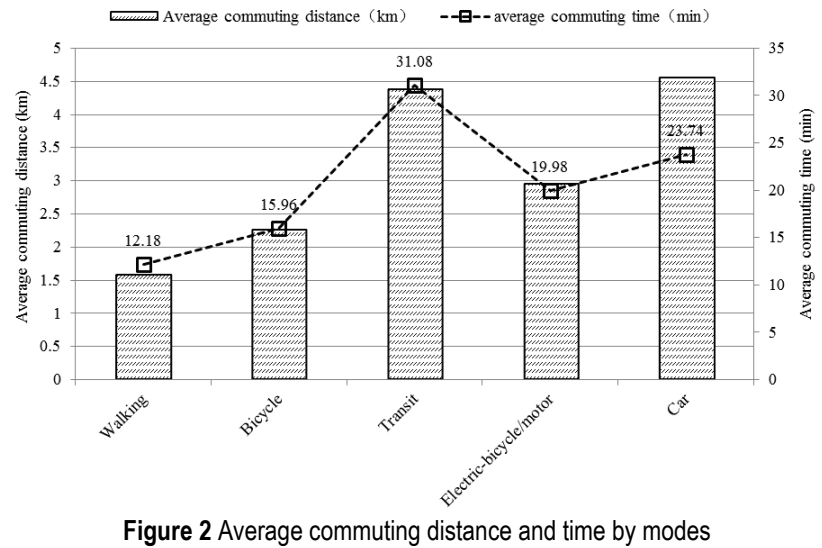

In the mode choice models of walking, transit, and electric-bicycle/motor, the coefficients of the car availability are all negative $(-0.248,-1.372,-0.943)$, which manifests that commuters with car availability tend to decrease the probability of choosing these modes. However, in the car mode choice model, commuters with car availability are the significant positive impact factors with the coefficient of 4.035. Compared with these four models, it is seen that if households own a car, there will be transfers from the modes of walking, transit, and electric-bicycle/motor to the car mode.

Household annual income is another important factor of the mode choice. In the mode choice model of transit and car, the coefficients of the household annual income indicate that commuters with lower household income tend to choose the transit, while the commuters with higher household income prefer the cars. Besides, commuters' ages also have impacts on the mode choice behaviours. Commuters of the age between 18 and 35 prefer the transit and do not tend to choose the car mode for commuting.
This result is related to the household income. The average household annual income of the commuters of the age between 18 and 35 is $3 \%$ lower than the average level of the samples. Therefore, if the household income increases, there will be transfers from the transit mode to the car mode.

The five mode choice model results in the typical city of Xi'an in China indicate that increasing commuting distance, commuting time, household income, and car ownership will all cause the increasing car uses. If there is long commuting distance, the shorter driving time is the important reason for the commuters choosing car rather than transit, and the lower household income is the reason for the commuters choosing the transit rather than car. Commuters with shorter distance prefer walking, bicycle and electric-bicycle/motor. For the low-carbon emission transportation development in Chinese cities, it is necessary to control the sharp increases of the car uses and to promote the use of transit and non-motorized traffic modes. However, Chinese cities are now experiencing rapid economic growth, urbanization and motorization, and are under the development process of city clusters. These will all inevitably cause the increasing number of the car ownerships, household incomes and commuting distances. Therefore, there is necessary to ensure the good transit service and to shorten the travel time of the transit.

Thus, countermeasures for the low-carbon emission transportation development in Chinese cities are suggested by the following: (1) great investment should be put on the high-quality public transit service; (2) public transit network should be optimized to improve the accessibility; (3) Policies of car restriction such as odd-and-even license plate rule, parking control, parking fees increasing, road congestion charging and transit priority lanes to shorten the travel time of riding buses should be combined together to meet commuter's demands of the comfortable, fast and convenient traveling; (4) compact, mixed land use development and transit oriented development (TOD) pattern should be implemented in the urban and transport planning in Chinese cities. Only by these measures combined together, will commuters with high income, car availability, and long trip distance use public transit instead of cars.

\section{CONCLUSION}

In this paper, the commuting mode choice models were established in the typical city of Xi'an in China by using the logistic regression modelling method. The significant factors of the mode choice behaviours were identified and the comparative analysis of the mode choice behaviours among the car and the low-carbon emission and non-motorized traffic modes (bus, walking, bicycle, and electric-bicycle/motor) was also made in this paper. Besides, this study revealed the characters and changing tendencies of the commuting mode choice behaviours in Chinese cities. It is found that: (1) the common factor of preferring the low-carbon emission and non-motorized traffic modes is the short commuting distance; commuters with long trip distance tend to prefer car and transit; (2) Car availability and higher household income are the significant factors for choosing the car mode while non possession of a car and lower household income are the significant factors of choosing the transit in the commuting 
trips; (3) Compared with the transit mode, shorter traveling time is the important factor for the commuters choosing the car mode; (4) There will be transfers from the walking, bicycle, electric-bicycle mode to the car and transit mode when there is increasing commuting distance; (5) There will be transfers from the transit mode to the car mode when there is increasing car availability and household income. Under the process of the rapid economic growth, urbanization and motorization and the process of the city cluster developments in Chinese cities, there will be great challenges of sharp increase of the transportation carbon emissions facing with the Chinese cities due to the sharp increase of the car availability, household income and commuting distance. Thus, for the low-carbon emission transportation development in Chinese cities, there is the necessity of improving the public transit services to shorten the traveling time and meet the demands of the comfort and convenient traveling, and this should be combined with traffic demand management measures such as odd-andeven license plate rule for cars, parking control, road congestion charging and transit priority lanes. Only by these measures combined together will commuters with high income, car availability, and long trip distance use public transit instead of cars. The findings in the typical city of Xi'an are not only useful to Chinese cities, but can also be of reference value for other cities in the world.

\section{Acknowledgement}

This study was funded by the National Natural Science Foundation of China (No. 51178055-E0807), The Fundamental Research Funds for the Central Universities of China (310821172201), and the Fundamental Research Funds for the Central Universities of China (310821172202).

\section{REFERENCES}

[1] (2007). Intergovernmental Panel on Climate Change (IPCC). Climate change 2007, The fourth IPCC Assessment Report.

[2] (2013). World Meteorological Organization (WMO). WMO Greenhouse Gas Bulletin.

[3] Brand, C., Goodman, A., Rutter, H., Song, Y. \& Ogilvie, D. (2013). Associations of individual, household and environmental characteristics with carbon dioxide emissions from motorised passenger travel. Applied Energy, 104, 158169. https://doi.org/10.1016/j.apenergy.2012.11.001

[4] JLL (Jones Lang LaSalle). (2015). China 60: from fast growth to smart growth. http://www.jll.com/china60/en-gb (Accessed on 16.03.2016)

[5] Zhang, J., Fujiwara, A., \& Soe, T. (2008). Capturing Travellers' Stated Mode Choice Preferences under the Influence of Income in Yangon City, Myanmar. Journal of Transportation Systems Engineering and Information Technology, 8(4), 49-62. https://doi.org/10.1016/S1570-6672(08)60032-X

[6] Xianyu, J. \& Juan, Z. (2008). Travel Behaviour and Mode Choice of Urban Motorcycle. Journal of Transportation Systems Engineering and Information Technology, 8(5), 136-140.

[7] Santos, G., Maoh, H., Potoglou, D., et al. (2013). Factors influencing modal split of commuting journeys in mediumsize European cities. Journal of Transport Geography, 30, 127-137. https://doi.org/10.1016/j.jtrangeo.2013.04.005

[8] Salon, D. (2009). Neighbourhoods, cars, and commuting in New York City: A discrete choice approach. Journal of
Transportation Research Part A: Policy and Practice, 43(2), 180-196.

[9] Garcia-Sierra, M. \& Van den Bergh, J. (2014). Policy mix to reduce greenhouse gas emissions of commuting: A study for Barcelona, Spain. Journal of Travel Behaviour and Society, 1(3), 113-126. https://doi.org/10.1016/j.tbs.2014.06.001

[10] Wang, D. \& Chai, Y. (2009). The jobs-housing relationship and commuting in Beijing, China: the legacy of Danwei. Journal of Transport Geography, 17(1), 30-38. https://doi.org/10.1016/j.jtrangeo.2008.04.005

[11] Dargay, J. \& Hanly, M. (2007). Volatility of car ownership, commuting mode and time in the UK. Journal of Transportation Research Part A: Policy and Practice, 41(10), 934-948. https://doi.org/10.1016/j.tra.2007.05.003

[12] (2013). Xi'an Municipal Bureau of Statistics. Xi'an Statistical Yearbook of 2012. Beijing, China Statistics Press.

[13] Yang, L. (2010). Study on the Travel Behaviours and Characteristics. Thesis of the Master Degree of Engineering. Chang'an University, Xi'an.

\section{Contact information:}

Liu YANG, PhD, Lecturer

Corresponding author

Department of Urban and Rural Planning,

College of Urban and Environmental Sciences, Northwest University,

No. 1 XueFu Ave., Guodu Education and Hi-Tech Industries Zone,

Chang'an District, Xi'an, 710127, Shaanxi, P. R. China

E-mail: philoyl@163.com

Yuanqing WANG, Professor

Corresponding author

School of Highway, Chang'an University

P.O. Box 487, Chang'an University,

Middle Section of South 2nd Ring Rd., Xi'an, 710064, P. R. China

E-mail: wyq21@vip.sina.com 